Azizoğlu, N. i. ve Okur, A. (2020). Üniversite öğrencilerinin okuma stratejileri üstbilişsel farkındalıklarının demografik değişkenler ve günlük ritim özellikleri ile ilişkisi. Ana Dili Eğitimi Dergisi, 8(2), 258-269.

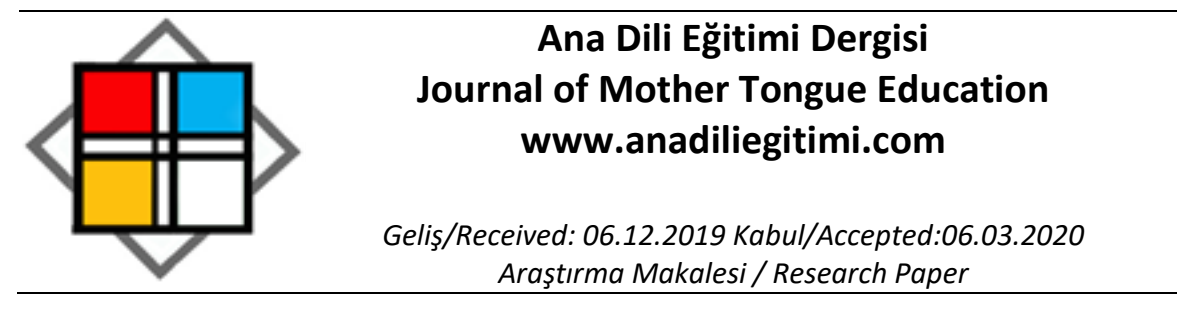

\title{
Üniversite Öğrencilerinin Okuma Stratejileri Üstbilişsel Farkındalıklarının Demografik Değişkenler ve Günlük Ritim Özellikleri ile İlişkisi
}

\author{
Nahide irem AZizOĞLU* \\ Alpaslan OKUR ${ }^{* *}$
}

\begin{abstract}
Öz
Okuma günlük hayatta sıkça kullanılan ve bireyin öğrenim hayatına yön vermesi açısından önemli olan bir beceri alanıdır. Okuma becerisinin geliştirilmesi, zayıf okuyucuların daha iyi okuyucular hâline gelmesinin sağlanması ve bireylerin okuma alışkanlığını kazanmaları Türkçe dersinin hedeflerinden biridir. Okuma becerisi sadece Türkçe dersi ile ilgili gibi görünse de öğrencinin diğer alanlardaki başarısı ve öğrenme düzeyi okuduğunu anlama becerisinden geçmektedir. Bu nedenle okuma becerisini geliştirmeye ve okuduğunu anlama düzeyini artırmaya yönelik farklı çalışmalar yapılmaktadır. Okuma becerisi karmaşık bir bütünden oluştuğundan okumanın geliştirilmesinin pek çok farklı yolu bulunmaktadır. Bu yollardan biri bireylerin okuma stratejilerini etkili kullanmalarından geçmektedir. Bu araştırmada üniversite öğrencilerinin okuma stratejileri üstbilişsel farkındalıklarının etkilendiği değişkenleri belirlemek amaçlandığından araştırma problemi "Üniversite öğrencilerinin cinsiyet, yaş ve günlük ritim özellikleri okuma stratejileri üstbilişsel farkındalıklarını anlamlı düzeyde yordamakta mıdır?" olarak belirlenmiştir. Araştırma korelasyonel bir araştırmadır ve araştırmaya Sakarya Üniversitesi Eğitim Fakültesi'nde formasyon eğitimi alan 818 öğrenci katılış̧ır. Araştırmada bağımlı değişken katılımcıların okuma stratejileri üstbilişsel farkındalıkları, bağımsız değişkenler bağımlı değişken üzerinde etkileri incelenen cinsiyet, yaş ve günlük ritim özellikleridir. Araştırmada okuma stratejileri üstbilişsel farkındalık ölçeği, günlük ritim ölçeği, kişisel bilgi formu kullanılarak veriler toplanmış ve verilerin analizinde SPSS 20 programı kullanılmışır. Araştırma bulgularına göre öğrencilerin okuma stratejileri üstbilişsel farkındalıkları yaş, cinsiyet ve günlük ritim özelliklerinden etkilenmektedir. Araştırma sonuçlarına göre öğrencilerin yaşı arttıkça okuma stratejileri üstbilişsel farkındalıkları artmaktadır. Ayrıca kadınların okuma stratejileri üstbilişsel farkındalıkları daha fazladır. Günlük ritim tercihleri açısından okuma stratejileri üstbilişsel farkındalıklar incelendiğinde gündüzcü ritim tercihi olan öğrencilerin okuma stratejileri üstbilişsel farkındalığııın daha yüksek olduğu tespit edilmiştir.
\end{abstract}

Anahtar Kelimeler: Okuma stratejileri, üstbiliş, günlük ritim.

\begin{abstract}
The Relationship Between Metacognitive Awareness Of Reading Strategies and Demographic Variables, Circadian Rhythm Characteristics Among University Students Abstract

Reading skills are commonly used in daily life and is a critical skill area as they affect an individual's learning life. One of the outcomes in the Turkish language lesson is to improve students' reading skills, to make students better readers and to enable them to require reading habit. Although reading skills seem to be associated with the Turkish language lesson, the success of students in other areas and their learning level depend on reading comprehension skills. Thus, efforts have been made to improve reading skills and increase reading comprehension levels. As
\end{abstract}

\footnotetext{
* Arş. Gör. Dr., Sakarya Üniversitesi, Eğitim Fakültesi, Türkçe ve Sosyal Bilimler Eğitimi Bölümü, Sakarya, azizoglu@sakarya.edu.tr, ORCID: 0000-0003-2738-9856

** Prof. Dr., Sakarya Üniversitesi, Eğitim Fakültesi, Türkçe ve Sosyal Bilimler Eğitimi Bölümü, Sakarya, aokur@sakarya.edu.tr, ORCID: 0000-0002-2868-063X
} 
reading skills are of complex nature, there are many different ways to improve one's reading. One of them is the effective use of reading strategies. Since this study aims to determine the variables that affect the metacognitive awareness of students towards reading strategies, it investigates the following research question: "Do the variables of gender, age and circadian rhythm characteristics significantly predict the university students' metacognitive awareness of reading strategies?" The research is a correlational research and 818 students who received pedagogical formation training at Sakarya University Faculty of Education participated in the research. In the research, dependent variable is metacognitive awareness of reading strategies, independent variables are gender, age and circadian rhythm characteristics. In the research, data were collected using reading strategies metacognitive awareness scale, daily rhythm scale, personal information form and SPSS 20 program was used in the analysis of the data. The findings of the study indicate that the metacognitive awareness of university students towards reading strategies is affected by their age, gender and circadian rhythm characteristics. The study concludes that the older the student is, the higher his/her metacognitive awareness towards reading strategies is. Further, the meta-cognitive awareness of female students towards reading strategies is higher. In regard to circadian rhythm characteristics, the study reveals that the metacognitive awareness of the students who prefer a morningness circadian rhythm towards reading strategies is higher.

Keywords: Reading strategy, metacognition, circadian rhythm.

\section{Okuma Stratejileri}

\section{Giriş}

Yazının harflerini, sözcüklerini, imlerini tanımak ve bunların anlamlarını kavramak (Göğüş, 1978: 60) anlamına gelen okuma, bireyin bilgi edinmesinin en temel yoludur. Bireyin dış dünya ile bağını kuran okumanın tüm hayatı etkileyen ve günlük hayatta sıkça kullanılan bir beceri alanı olduğu açıktır. Bu nedenle öğrencilerin okuma becerilerini geliştirmek, okuduklarını anlama seviyelerini arttırmak Türkçe dersinin temel amaçlarından biridir. Öğrencilerin okuma becerilerinin gelişmesi iyi birer okuyucu olmalarını sağlayacaktır.

İyi okuyucu okuma stratejilerini kullanır, okuma amacını bilir, okuma esnasında yaşayabileceği sorunlara ilişkin çözüm önerileri vardır, kelime bilgisi iyi düzeydedir, metinden çıkarımlar yapabilir, anlama sürecini kontrol eder, metne yönelik tahminler yapar, metnin içeriğini analiz edebilir, eski ve yeni bilgilerini karşılaştırabilir, metne ilişkin anahtar kelimeleri belirleyebilir, metnin ana fikrini bulabilir, dikkatini metne verebilir, metni anlama sürecini kontrol edebilir. Ancak okuma becerisi zayıf olan okuyucu dikkatini metne veremez, kaygı duyar, metin üzerinde düşünmeden okumaya geçer, önceki bilgileri ile metin arasında bağ kuramaz, önemli bilgileri ayırt edemez, anlama sürecini kontrol etme becerisinden yoksundur (Bråten, Amundsen ve Samuelstuen, 2010; Kuruyer ve Özsoy, 2016; Palincsar ve Brown, 1984; Paris ve Jacobs, 1984; Pressley ve Afflerbach, 1995; Schmitt ve Hopkins, 1993; Snow, Burns ve Griffin, 1998; Yang, 2002). İyi okuyucuların özellikleri incelendiğinde, iyi okuyucuların zayıf okuyucunun aksine okumaya başlamadan önce, okuma esnasında ve okuma sonrasında planlı bir şekilde okumaya yönelik bazı uygulamalar yaptıkları görülmektedir. Yapılan bu uygulamaların çoğu okuma stratejileri kavramının içerisinde yer almaktadır. Bu nedenle okuma stratejilerini etkili kullanabilmek iyi okuyucuların en önemli özelliklerinden biridir.

Okuma stratejileri okuma sırasında karşılaşılan problemleri çözmeye yardımcı, okumanın verimini arttıran, bireyin anlama düzeyini geliştirmesine katkı sağlayan tekniklerdir (Akkaya, 2011: 70). Konuya ilişkin literatür incelendiğinde, okuma stratejilerinin etkili kullanımının okuduğunu anlamayı geliştirdiğini gösteren çalışmaların (Akkaya, 2011; Başaran, 2013; Cantrell ve Carter, 2009; Güngör ve Ün-Açıkgöz, 2006; Temizkan, 2008) bulunduğu görülmektedir. Bu durum okuma stratejilerinin etkili kullanımının iyi okuyucuların birer özelliği olduğunu kanıtlar niteliktedir.

Okuma stratejileri literatürde okuma öncesinde, okuma esnasında ve okuma sonrasında kullanılan stratejiler olarak ayrılmaktadır. Okuma öncesinde kullanılan stratejiler okuma amacını belirleme, metnin türünü ve okuma hızını belirleme, görsellerden hareketle yorum yapma, metni gözden geçirme, yapılan çıkarımları başkalarıyla paylaşma, giriş ve sonuç bölümlerini gözden geçirme, 
anahtar kelimeleri belirleme, metnin içeriğini tahmin etme, okuma yöntem ve tekniğini belirleme, ana ve alt başlıkları/metnin yazarını inceleme, metnin uzunluğu, yapısı gibi özelliklerini inceleme, grafik düzenleyiciler kullanma olarak açıklanmaktadır. Okuma esnasında kullanılan stratejiler bilinmeyen kelimelerinin anlamını tespit etmeye çalışma, metnin amacını belirlemeye çalışma, metinle ilgili sorulara cevap arama, önemli bilgileri belirleme, önemli yerleri not alma, anahtar kelimeleri işaretleme, anlama ve zihinde yapılandırma, bilgiyi uygulamaya çalışma, dikkat dağılınca okunan kısma geri dönme, sözlük gibi başvuru kaynakları kullanma, okuma sürecinde anladıklarını düşünme, okunanları zihinde canlandırma şeklindedir. Okuma sonrasında kullanılan stratejiler metinden sonuç çıkarma, okuma esnasında alınan notları/işaretlemeleri gözden geçirme, metni özetleme, okunanları tartışma, metinle ilgili soruları cevaplama, metinle ilgili anlamsal harita oluşturma, metni eleştirme, metnin içeriğinin okuma amacı ile uyumunu değerlendirme, metindeki bilgileri günlük hayat açısından değerlendirme, metinde verilen bilgileri ve ana fikri eleştirel bir bakış açısıyla inceleme olarak açıklanmaktadır (Akkaya, 2011; Baydık, 2011; Cantrell ve Carter, 2009; Epçaçan, 2009; Erdağı-Toksun, 2018; Güneş, 2013; Karadağ ve Yurdakal, 2016; Karatay, 2014; Ülper, 2010). Okuma öncesinde kullanılan stratejilerin bireyi okuma sürecine ve okunacak metne hazırladığı, okuma sürecinde kullanılan stratejilerin metni tam olarak anlama ve anlatılanları kavrama üzerinde yoğunlaştığı, okuma sonrasında kullanılan stratejilerin okunanları değerlendirme ve yorumlama etkinliklerine odaklandığı söylenebilir.

\section{Okuma ve Üstbilişsel Farkındalık}

Üstbiliş kavramının anlamının kelimenin kökeni olan "meta" kelimesine dayanmaktadır. Meta, Roma dönemindeki yarışlarda yarışın dönüm noktasını işaretlemek için meydanda yer alan sütunlardan birinin adıdır ve üstbiliş burada olduğu gibi zihindeki anlamanın dönüm noktası olarak açıklanabilir (Fisher, 1998: 1). Literatürde üstbiliş, bilişötesi, bilişüstü gibi terimlerle ifade edilen kavram üzerine farklı tanımlamalar bulunmaktadır. Üstbiliş bireyin kendisinin (ne yaptığının, nasıl yaptığının) ve sürecin (neleri hangi sıra ile yaptığı, ne elde ettiği) farkında olması (Çakıroğlu ve Ataman, 2008: 2), bireyin kendi bilişsel süreçlerini gözlemlemesi ve düşünme süreci hakkında düşünmesi (Babbs ve Moe, 1983: 423) olarak açıklanmaktadır. Tanımlardan hareketle üstbilişin bireyin bilişsel süreçlerinin farkında olmasına dayandığı yorumuna ulaşılabilir.

Üstbiliş kavramı üstbilişsel bilgi ve üstbilişsel kontrol basamaklarını içermektedir. Üstbilişsel bilgi yordam bilgisi, bildirimsel bilgi ve duruma dayalı bilgi basamaklarını kapsar. Yordam bilgisi bir işlemin nasıl yapılacağını bilme, bildirimsel bilgi bireyin işlemi yapıp yapamayacağını bilmesi, duruma dayalı bilgi bireyin karşılaştı̆̆ı bir durumda yapılması gerekenleri bilmesi, bilgiyi işleme dökebilmesi anlamlarına gelmektedir. Üstbilişsel kontrol basamakları tahmin, planlama, izleme ve değerlendirmedir. Tahmin aşamasında birey göreve yönelik varsayımlarda bulunur, planlamada görevi gerçekleştirmeye yönelik bir plan hazırlar, izleme basamağında uygulamaya yönelik düzenlemeler yapar ve değerlendirme basamağında ise uygulamayı değerlendirir (Özsoy, 2008: 717). Ku ve Ho (2010: 252) üstbilişin bilgi ve düzenleme olmak üzere iki bileşeni olduğundan bahseder. Bilgi kısmı bireyin kendi bilişsel süreçlerine ilişkin bilgisidir. Düzenleme kısmı bireyin bilişsel süreçlerini kontrol edebilmek adına hâlihazırda kullandığı stratejilerin bileşimidir.

Üstbilişsel farkındalık bireyin neyi bilip bilmediğinin farkında olması, kendisinin ve çevresindekilerin bilişsel süreçlerinin farkında olması, kendi zihinsel süreçlerini kontrol etmesi, öğrenme sorumluluğunu alması, öğrenme stratejilerinin farkında olması, öğrenmesini değerlendirmesi, planlaması, izlemesi ve bilgisini yönetme stratejilerini kullanmasını içermektedir (Bağçeci, Döş ve Sarıca, 2011: 552). Üstbilişsel becerileri gelişmiş kişiler yetenek ve becerilerinin farkındadır, öğrenme yöntemini seçebilir, öğrenme stratejilerini etkili bir biçimde kullanır, öğrenme sürecinde başarılıdır, kendi öğrenme sürecini değerlendirebilir, önceki bilgilerini etkili biçimde kullanabilir, sorunlara uygun çözüm yolları bulabilir ve bu sorunlara yönelik eylem planı hazırlayabilir, ne/niçin/nasıl/ne zaman gibi sorularla herhangi bir konu üzerinde inceleme yapabilir. Bu nedenle sorgulama becerileri gelişmiştir (Anderson, 2002; Fisher, 1998; Mason ve Santi, 1994; Ormrod, 2012; Şen, 2012). 
Okumada kullanılan bilişsel stratejiler not alma, özetleme, önceki bilgileri kullanma, çıkarımlar yapma, tahmin etme, ipuçlarını analiz etme olarak açıklanabilir ancak üstbilişsel stratejiler öğrenme sürecini düzenlemeye dayandığından özdeğerlendirme ve okuma hakkında düşünme ile ilgilidir (O'Malley ve Chamot, 1990; Oxford, 1990). Okumada üstbiliş bireyin okuma sürecinde kendini izleme ve değerlendirme aşamalarına dayanmaktadır. Okunacak metne uygun strateji ve becerilerin seçilmesi okumada üstbilişsel becerilerin kullanıldığının bir göstergesidir. Okuma süreci bireyin üstbilişsel becerileri ile başlar ve okuma stratejilerinin kullanılması ile son bulur (Babbs ve Moe, 1983; Zhang ve Wu 2009).

Bireyin okumada üstbilişsel fakındalığı okuma sürecine ilişkin bilişsel bilgisi ve okuma anlama sürecini düzenlemek için kullandığı denetim yöntemleri ile ortaya çıkmaktadır (Sheorey ve Mokhtari, 2001: 432). Jacobson (1998: 587) okumada üstbilişsel beceriler konusunda bireyin kendi davranışlarının farkında olmasının öneminden bahseder. Birey okuma esnasında metindeki bir paragrafın anlamayı zorlaştıran veya kolaylaştıran özelliklerinin farkındaysa okumaya yönelik üstbilişsel becerilerini kullanıyor demektir. Ancak birey bilmediği kelimeyi anlamak için metni yeniden okusa bile bu davranışının farkında değilse davranışı üstbiliş ile açıklamak doğru değildir. Bu örnek üstbilişsel becerilerin kullanımında bireyin farkındalığının önemini açıklar niteliktedir.

Üstbilişsel becerilerin kullanıldığı okuma sürecinde okuyucu okuma sürecini kontrol etme, okuma amacını belirleme, okuma sürecini planlama ve bu sürece uygun stratejiyi seçme, üstbilişsel stratejileri okuma sürecinde kullanma, okuma sürecindeki başarısını değerlendirme becerilerine sahip olmalıdır (Babbs ve Moe, 1983; Zhang ve Wu, 2009). Bu becerilere sahip olan bireylerin daha iyi okuyucu oldukları, okuma sürecini daha etkili yönetebildikleri söylenebilir. Okuma problemi yaşayan bireylerin okuma esnasında daha az sayıda ve daha basit düzeyde üstbilişsel stratejileri kullandıkları bilinmektedir (Padeliadu, Botsas ve Sideridis, 2002). İyi okuyucuların üstbilişsel becerileri okumada kullandıkları, zayıf okuyucuların üstbiliş eğitiminden sonra okuma becerisinde gelişme gösterdiğini açıklayan çalışmalar bulunmaktadır (Eker, 2014; Çakıroğlu ve Ataman, 2008; Çubukçu, 2008; Houtveen ve van de Grift, 2007; Kolić-Vehovec ve Bajšanski, 2006; Paris, Cross ve Lipson, 1984).

Okuma becerisi pek çok fiziksel ve zihinsel işlemi barındıran karmaşık bir bütündür. Bu nedenle okuma becerisinin geliştirilmesinin sadece bir yolu olduğunu söylemek doğru değildir. İyi okuyucuların pek çok niteliğe sahip oldukları ve zayıf okuyucuların alacakları eğitimlerle iyi birer okuyucu olabilecekleri bilinmektedir. Okuma sürecinin etkililiğinin arttırılmasının ve okuduğunu anlama düzeyinin gelişmesinin yollarından biri okuyucunun okunacak metne ilişkin uygun stratejiyi seçebilmesi ve uygulayabilmesidir. Ancak seçilen stratejinin uygulanması esnasında bireyin kendi okuma sürecini kontrol edebilmesi, ortaya çıkan sorunlara çözüm yolları bulabilmesi okuyucunun üstbilişsel farkındalığının seviyesi ile ilgilidir.

Literatürde okuma stratejileri üstbilişsel farkındalığı cinsiyet değişkeni (Duran, 2011; Karatay, 2010) ve yaş değişkeni (Cantrell ve Carter, 2009; Erdem, 2012) açısından ele alan araştırmalar mevcut olmasına rağmen bu araştırmalarda farklı sonuçlar elde edilmiştir. Bu nedenle okuma stratejileri üstbilişsel farkındalığın cinsiyet ve yaş değişkenleri ile ilişkisinin yeniden ele alınması gereklidir. Ayrıca bireylerin zihinsel süreçlerinin günlük ritim özelliklerinden etkilenmesinden (Rothen ve Meier, 2016) dolayı araştırmada daha önce ele alınmayan bireylerin günlük ritim tercihlerinin okuma stratejileri üstbilişsel farkındalıkları ile ilişkisi incelenmiştir. Bireylerin okuma stratejileri üstbilişsel farkındalıklarının hangi değişkenlerden etkilendiğinin incelenmesi, okuma becerisinin geliştirilmesi konusunda öğrencilere ve eğitimcilere yardımcı olacak ve konuyla ilgili literatüre katkı sağlayacaktır. Bu nedenle bu araştırmanın amacı "Üniversite öğrencilerinin cinsiyet, yaş ve günlük ritim özellikleri okuma stratejileri üstbilişsel farkındalıklarını anlamlı düzeyde yordamakta mıdır?" olarak belirlenmiştir.

\section{Araştırmanın Modeli}

\section{Yöntem}

Araştırma iki ya da daha fazla değişken arasındaki ilişkileri belirlemek ve neden-sonuç ilişkileri hakkında ipuçları elde edilmek için yapılan korelasyonel bir araştırmadır (Büyüköztürk, Kılıç-Çakmak, Akgün, Karadeniz ve Demirel, 2012: 15). Bu araştırmanın bağımlı değişkeni katılımcıların okuma 
stratejileri üstbilişsel farkındalık puanlarıdır. Araştırmanın bağımsız değişkenleri bağımlı değişken üzerinde etkileri incelenen cinsiyet, yaş ve günlük ritim özellikleri olarak belirlenmiştir.

\section{Örneklem / Araştırma grubu}

Araştırmaya 2015-2016 öğretim yılı bahar döneminde Sakarya Üniversitesi Eğitim Fakültesi'nde formasyon eğitimi alan 818 öğrenci katılmıştır. Araştırmada formasyon eğitimi alan öğrencilerin tamamına ulaşııması hedeflendiğinden amaçlı örnekleme yöntemlerinden maksimum çeşitlilik örnekleme yöntemi seçilerek farkı bölümlerde öğrenim gören öğrencilerin katılımı sağlanmaya çalışımıştır. Katılımcıların öğrenim gördükleri lisans programlarının dağıımı Tablo 1'de gösterilmiştir.

Tablo 1.

Örneklemde Yer Alan Öğrencilerin Lisans Programlarına Göre Dağılımı

\begin{tabular}{lll}
\hline Lisans Programı & $f$ & $\%$ \\
\hline Biyoloji & 26 & 3,2 \\
Coğrafya & 33 & 4,0 \\
Diğer & 19 & 2,3 \\
Felsefe & 30 & 3,7 \\
Fizik & 25 & 3,1 \\
Güzel Sanatlar & 46 & 5,6 \\
Ilahiyat & 141 & 17,2 \\
Kimya & 39 & 4,8 \\
Konservatuar & 17 & 2,1 \\
Matematik & 44 & 5,4 \\
Sağlık Bilimleri & 50 & 6,1 \\
Sosyoloji & 27 & 3,3 \\
Spor Bilimleri & 78 & 9,5 \\
Tarih & 72 & 8,8 \\
Türk Dili ve Edebiyatı & 82 & 10,0 \\
Yabancı Diller & 89 & 10,9 \\
Toplam & 818 & 100 \\
\hline
\end{tabular}

Tablo 1 incelendiğinde araştırmanın örneklem grubunda en fazla ilahiyat (\%17), en az konservatuar (\%2) lisans programından öğrenci bulunduğu görülmektedir. Araştırmaya katılan öğrencilerin $\% 75^{\prime} i$ kadın $\% 25^{\prime}$ i erkektir. Öğrencilerin yaş ortalaması 26,2 ve bu değişkenin standart sapması 4,6'dır.

\section{Veri Toplama Araçları}

Araştırmada veri toplama aracı olarak okuma stratejileri üstbilişsel farkındalık ölçeği, günlük ritim ölçeği ve kişisel bilgi formu kullanılmıştır. Bu ölçme araçları ile ilgili detaylı bilgiler aşağıda yer almaktadır.

Okuma Stratejileri Üstbilişsel Farkındalık Ölçeği. Araştırmanın verilerinin toplanmasında Mokhtari ve Reichard (2002) tarafından geliştirilen Türkçeye Öztürk (2012) tarafından uyarlanan "Okuma Stratejileri Üstbilişsel Farkındalık Ölçeği" kullanılmıştır. Ölçek 30 maddeden oluşmaktadır. Üstbilişsel strateji farkındalı̆ııı belirlemeye ilişkin maddelerden oluşan ölçek beşli likert tipindedir (asla ya da neredeyse hiç, nadiren, ara sıra, genellikle, daima ya da neredeyse her zaman). Ölçekten alınabilecek en düşük puan 30, en yüksek puan 150'dir. Ölçeğin tamamı için Cronbach's Alfa değeri ,93 olarak bulunmuştur. Genel okuma stratejisi, problem çözme stratejisi, okuma stratejilerini destekleme alt boyutları için Cronbach's Alfa değerleri sırasıyla ,85; ,76; ,81 olarak hesaplanmıştır. Ölçeğin açıkladığı toplam varyans $\% 42,6$ 'dır.

Günlük Ritim Ölçeği. Öğrencilerin günlük ritim özellikleri Smith, Reilly ve Midkiff (1989) tarafından geliştirilen; Önder, Beşoluk ve Horzum (2013) tarafından Türkçeye uyarlanan ölçek ile 
belirlenmiştir. Ölçek bireylerin günün hangi zaman diliminde daha aktif olduklarını belirlemeyi amaçlamaktadır. Ölçekte çoktan seçmeli 13 madde bulunmaktadır ve ölçekten alınabilecek en düşük puan 13, en yüksek puan 55'tir. Ölçekten alınan yüksek puanlar bireyin daha çok gündüz aktif olduğunu, düşük puanlar bireyin daha çok gece aktif olduğunu göstermektedir. Cronbach's Alfa değeri ölçek geneli için ,80 olarak hesaplanmıştır

Kişisel Bilgi Formu. Araştırmaya katılan öğrencilere ilişkin cinsiyet ve yaş bilgileri hazırlanan kişisel bilgi formu ile toplanmıştır.

\section{İşlem / Verilerin Toplanması}

Araştırma için Sakarya Üniversitesi Eğitim Fakültesi'den izin alınmıştır ve tüm öğrencilere açıklama yapılarak araştırmaya gönüllü olarak katılmaları istenmiştir. Araştırmanın verileri GoogleFormlar kullanılarak toplanmıştır.

\section{Verilerin Analizi}

Veriler yordanan değişken olarak öğrencilerin okuma stratejileri üstbilişsel farkındalıklarının alındığı ve cinsiyet, yaş ve günlük ritim özelliklerinin yordayıcı olarak kullanıldığı hiyerarşik regresyon analizi kullanılarak analiz edilmiştir. Analize kategorik değişken olarak yalnızca cinsiyet değişkeni eklenmiştir. Kadınlar 0, erkekler 1 olarak kodlanmıştır. Analize ilk blokta demografik değişkenler olan cinsiyet ve yaş değişkenleri eklenmiştir. İkinci blokta günlük ritim özellikleri değişkeni analize dahil edilmiştir. Araştırmanın verileri regresyon analizi sayıltıları bakımından incelenmiştir. Veri setindeki uç değerler standardize edilmiş hatalar yöntemi ile incelenmiş ve kabul edilen \pm 3 aralığında olmayan veriler çıkartılmış, analizler 818 veri üzerinden yapılmıştır. Analizler SPSS 20 programı ile gerçekleştirilmiştir.

\section{Bulgular}

Araştırmada incelenen değişkenler arasındaki korelasyon değerleri Tablo 2'de verilmiştir.

Tablo 2.

Değişkenler Arası Korelasyonlar

\begin{tabular}{|c|c|c|c|c|}
\hline Değişkenler & Cinsiyet & Yaş & GRÖ & OSÜF \\
\hline Cinsiyet** & &,$- 03 *$ & ,03* &,$- 18^{*}$ \\
\hline Yaş & & & ,23* & ,11* \\
\hline GRÖ & & & & ,10* \\
\hline OSÜF & & & & $1,00 *$ \\
\hline
\end{tabular}

GRÖ=Günlük ritim özellikleri, OSÜF=Okuma stratejileri üstbilişsel farkındalık değişkenleridir.

$* p<, 01$

**Cinsiyet: $0=$ kadın, $1=e r k e k$ kodlanmıştır.

Tablo 2 incelendiğinde yaş değişkeni ile günlük ritim özellikleri değişkeni arasında pozitif yönde düşük düzeyde anlamlı ilişki $(r=, 23 ; p<, 01)$, yaş değişkeni ile okuma stratejileri üstbilişsel farkındalık değişkeni arasında pozitif yönde düşük düzeyde anlamlı ilişki $(r=, 11 ; p<, 01)$ olduğu görülmektedir. Ayrıca günlük ritim özellikleri değişkeni ile okuma stratejileri üstbilişsel farkındalık değişkeni arasında pozitif yönde düşük düzeyde anlamlı ilişki $(r=, 10 ; p<, 01)$ bulunmaktadır.

Okuma stratejileri üstbilişsel farkındalığın cinsiyet, yaş ve günlük ritim özellikleri değişkenleri ile ilişkisine ilişkin hiyerarşik regresyon analizi sonuçları Tablo 3'te verilmiştir.

Tablo 3.

Okuma Stratejileri Üstbilişsel Farkındalığın Yordanmasına Iliş̧kin Hiyerarşik Regresyon Analizi Sonuçları

\begin{tabular}{|c|c|c|c|c|c|c|}
\hline Model & Yordayıcı & $B$ & $S H_{B}$ & B & $t$ & $p$ \\
\hline
\end{tabular}


1

Cinsiyet
Yaş

$-6,96$

, 37

103,89
1,28

, 11

3,21
,- 18
, 10

$-5,42$

3,09

32,36
, 000

, 002

,000

Blok 2: $R=, 23 ; R^{2}=, 055 ; \Delta R 2=, 052 ; F(3,813)=15,821 ; p<, 01$

\begin{tabular}{|c|c|c|c|c|c|}
\hline Cinsiyet & $-7,10$ & 1,28 &,- 19 & $-5,55$ & ,000 \\
\hline Yaş & ,29 & ,28 & ,08 & 2,38 & ,017 \\
\hline GRÖ* & ,23 & ,08 & ,09 & 2,65 & ,008 \\
\hline Sabit & 100,87 & 3,39 & & 29,72 & ,000 \\
\hline
\end{tabular}

*GRÖ=Günlük ritim özellikleri

$R=, 24 ; R^{2}=, 05 ; F=12,79 ; p<, 01$

Değişkenler analize iki blok halinde dâhil edilmiştir. Analize birinci sırada (blokta) demografik değişkenler olan cinsiyet ve yaş değişkenleri, ikinci sırada (blokta) günlük ritim özellikleri değişkeni alınmıştır. Cinsiyet değişkeni $0=$ kadınlar, $1=$ erkekler şeklinde kodlanmıştır. Durbin-Watson=1,92; tolerans değerleri ,94 ve ,99 aralığında; VIF değerleri 1,00 ve 1,07 aralığındadır. Durbin-Watson değeri 2'ye yakındır ve değişkenler arasında otokorelasyon görülmemiştir. Tolerans değerleri ,20'den büyüktür ve VIF değerleri 5'ten küçüktür. Çoklu bağlantılılık bulunmamaktadır.

Analize birinci sırada (blokta) cinsiyet ve yaş değişkenleri alınmıştır. Regresyon analizi sonuçlarına göre cinsiyet $(\beta=-, 18 ; p<, 01)$ ve yaş $(\beta=, 10 ; p<, 01)$ değişkenlerinin okuma stratejileri üstbilişsel farkındalığın anlamlı bir yordayıcısı olduğu görülmektedir. Bu bulgular yaş artıkça okuma üstbilişsel farkındalı̆̆ının arttı̆̆ını göstermektedir. Bunun yanında kadınların okuma stratejileri üstbilişsel farkındalıklarının daha yüksek olduğu ortaya çıkmıştır. Bu değişkenler okuma stratejileri üstbilişsel farkındalığa ilişkin varyansın \%4,7'sini açıklamaktadır.

Analize ikinci sırada (blokta) günlük ritim değişkeni alınmıştır. Cinsiyet ve yaş değişkenleri kontrol edildiğinde günlük ritim değişkeninin okuma stratejileri üstbilişsel farkındalığın $(\beta=, 09 ; p<, 01)$ anlamlı bir yordayıcısı olduğunu görülmektedir. Bulgulara göre gündüzcü günlük ritim özelliği olan öğrencilerin okuma stratejileri üstbilişsel farkındalığııın daha yüksek olduğu ortaya çıkmıştır. Bu değişken okuma stratejileri üstbilişsel farkındalık değişkeninde daha önce açıklanan varyansa \%0, $8^{\prime}$ lik katkı sağlamaktadır. Böylece açıklanan toplam varyans \%5,5'e yükselmiştir.

\section{Tartışma ve Sonuç}

Araştırma sonuçlarına göre kadınların okuma stratejileri üstbilişsel farkındalıkları daha fazladır. Literatürde kadınların okuma stratejileri üstbilişsel farkındalıklarının (Karatay, 2010); üstbilişsel okuma farkındalıklarının (Bozkurt ve Memiş, 2013); üstbilişsel becerilerinin (Altındağ, 2008; Bağçeci, Döş ve Sarıca, 2011; iflazoğlu-Saban ve Saban, 2008; Kolić-Vehovec ve Bajšanski, 2006; Yavuz, 2009); okuma stratejilerini kullanma düzeylerinin (Cantrell ve Carter, 2009; Kolić-Vehovec ve Bajšanski, 2006; Topuzkanamış, 2009) daha iyi olduğunu belirleyen araştırmalar mevcuttur. Ancak üstbilişsel farkındalık düzeyinin cinsiyete göre farklılaşmadığını (Duran, 2011; Özsoy, Çakıroğlu ve Kuruyer, 2010; Özsoy ve Günindi, 2011; Padeliadu, Botsas ve Sideridis, 2002; Tüysüz, Karakuyu ve Bilgin, 2008); okuma stratejileri kullanımının cinsiyete göre farklılaşmadığını (Erdem, 2012; Özdemir, 2018) belirten araştırmalar mevcuttur. Araştırmada kadınlar lehine anlamlı bir farklıık bulunması seçilen örneklem grubunun özelliklerinden kaynaklanıyor olabilir. Bu nedenle yapılacak farklı çalışmalarda farklı örneklem gruplarında cinsiyet ve üstbilişsel beceriler ilişkisinin yeniden ele alınması faydalı olacaktır.

Araştırma sonuçlarına göre bireylerin yaşı arttıkça okuma stratejileri üstbilişsel farkındalıkları artmaktadır. Cantrell ve Carter (2009) yaşın okuma stratejilerini kullanma düzeyini etkileyen önemli bir değişken olduğunu belirtmektedir. Literatür incelendiğinde yaşla birlikte üstbilişsel becerilerin arttığını (Özsoy ve Günindi, 2011; Padeliadu, Botsas ve Sideridis, 2002; Tüysüz, Karakuyu ve Bilgin, 2008) tespit eden çalışmalar görülmektedir. Ancak strateji kullanımının yaşla birlikte artmadığını 
belirleyen araştırmalar (Baykara, 2011; Erdem, 2012) da mevcuttur. Üstbilişsel becerilerin kullanımı konusunda önemli olan yaş değil tecrübe kazanmaktır. Yaşı büyük olan bireyler daha fazla üstbilişsel bilgiyi özümsediklerinden daha başarılı olurlar (Fisher, 1998). Özellikle okuma stratejilerine ilişkin üstbilişsel farkındalık konusunda yaş değişkeninin etkisi literatürde tam olarak açıklanmamıştır. Bu nedenle yaş değişkeni ile okuma stratejileri üstbilişsel farkındalık ilişkisini farklı örneklem gruplarında ele alacak yeni çalışmalar literatüre katkıda bulunacaktır.

Araştırma sonuçlarına göre öğrencilerin günlük ritim özellikleri okuma stratejileri üsbilişsel farkındalıklarını etkilemektedir. Gündüzcü ritim tercihi olan öğrencilerin okuma stratejileri üstbilişsel farkındalıkları daha fazladır. Bireylerin zihinsel süreçlerinin (Hourihan ve Benjamin, 2013; Natale, Alzani, Cicogna, 2003; Rothen ve Meier, 2016), öğrenme becerilerinin (Gao, Terlizzese ve Scullin, 2019), öğrenme stratejilerinin (Ruffing, Hahn, Spinath, Brünken, Karbach, 2015), akademik başarılarının (Damar, 2016; Önder, Horzum ve Beşoluk, 2012) günlük ritim özelliklerinden etkilendiğini gösteren araştırmalar yapılmıştır. Bireylerin günün hangi zaman diliminde zihinsel olarak daha aktif oldukları öğrenim süreçlerini etkilemektedir. Bu nedenle bireylerin günlük ritim özellikleri hakkında yapılacak farklı çalışmalara ihtiyaç olduğu açıktır.

\section{Kaynaklar}

Akkaya, N. (2011). İlköğretim 8. Sınıf Türkçe Dersinde Okuduğunu Anlama Stratejilerini Kullanmanın Tutuma Etkileri. Millî Ĕgitim, 191, 68-77.

Altındağ, M. (2008). Hacettepe Üniversitesi Eğitim Fakültesi Öğrencilerinin Yürütücü Biliş Becerileri. (Yayımlanmamış yüksek lisans tezi). Hacettepe Üniversitesi/Eğitim Bilimleri Enstitüsü, Ankara.

Anderson, R. D. (2002). Reforming Science Teaching: What Research Says About Inquiry. Journal of Science Teacher Education, 13 (1), 1-12.

Babbs, P., Moe, A. (1983). Metacognition: A Key for Independent Learning From Text. The Reading Teacher, 36 (4), 422-426.

Bağçeci, B., Döş B., Sarıca R. (2011). İlköğretim Öğrencilerinin Üstbilişsel Farkındalık Düzeyleri İle Akademik Başarısı Arasındaki İlişkinin İncelenmesi. Mustafa Kemal Üniversitesi Sosyal Bilimler Enstitüsü Dergisi, 16, 551-566.

Başaran, M. (2013). 4. Sınıf Öğrencilerinin Üstbilişsel Okuma Stratejilerini Kullanma Durumları ve Bu Stratejilerle Okuduğunu Anlama Arasındaki Illişki. Electronic Turkish Studies, 8 (8), 225-240.

Baydık, B. (2011). Okuma Güçlüğü Olan Öğrencilerin Üstbilişsel Okuma Stratejilerini Kullanımı ve Öğretmenlerin Okuduğunu Anlama Öğretim Uygulamalarının İncelenmesi. Eğitim ve Bilim, 36 (162), 301-319. http://egitimvebilim.ted.org.tr/index.php/EB/article/viewFile/1354/330

Baykara, K. (2011). Öğretmen Adaylarının Bilişötesi Öğrenme Stratejileri ile Öğretmen Yeterlik Algıları Üzerine Bir Çalışma. Hacettepe Üniversitesi Eğitim Fakültesi Dergisi, 40, 80-92.

Bozkurt, M., Memiş, A. (2013). Beşinci Sınıf Öğrencilerinin Üstbilişsel Okuduğunu Anlama Farkındalı̆ı̆ ve Okuma Motivasyonları ile Okuma Düzeyleri Arasındaki İlişki. Ahi Evran Üniversitesi Eğitim Fakültesi Dergisi, 14 (3), 147-160.

Bråten, I., Amundsen, A., Samuelstuen, M. S. (2010) Poor Readers-Good Learners: A Study of Dyslexic Readers Learning With and Without Text. Reading and Writing Quarterly, 26 (2), 166-187. doi: 10.1080/10573560903123684

Büyüköztürk, Ş., Kılıç Çakmak, E., Akgün, Ö. E., Karadeniz, Ş. \& Demirel, F. (2012). Bilimsel Araştırma Yöntemleri. Ankara: Pegem A.

Cantrell, S., Carter, J. (2009). Relationships Among Learner Characteristics and Adolescents' Perceptions About Reading Strategy Use. Reading Psychology, 30, 195-224. doi: $10.1080 / 02702710802275397$

Çakıroğlu, A., Ataman, A. (2008). Üstbilişsel Strateji Öğretiminin Okuduğunu Anlama Başarı Düzeyi Düşük Öğrencilerde Erişi Artırımına Etkisi. Sakarya Üniversitesi Eğitim Fakültesi Dergisi, 16, 113.

Çubukçu, F. (2008). Enhancing Vocabulary Development and Reading Comprehension Through Metacognitive Strategies. Educational Research, 18 (1), 1-11. 
Damar, A. (2016). Özerk Öğrenme, Günlük Ritim, Sosyal Jetlag ve Ortalama Uyku Süresi ile Fen Başarısı Arasındaki ilişski. (Yayımlanmamış yüksek lisans tezi). Sakarya Üniversitesi/Eğitim Bilimleri Enstitüsü, Sakarya.

Duran, S. (2011). Illköğretim Öğretmenlerinin Bilişsel Farkındalık Düzeylerinin Çeşitli Değişkenlere Göre Incelenmesi. (Yayımlanmamış yüksek lisans tezi), Kafkas Üniversitesi/Sosyal Bilimler Enstitüsü, Kars.

Eker, C. (2014). The Effect of Teaching Practice Conducted by Using Metacognition Strategies on Students' Reading Comprehension Skills. IOJES, 6 (2), 269-280.

Epçaçan, C. (2009). Okuduğunu Anlama Stratejilerine Genel Bir Bakış. Uluslararası Sosyal Araştırmalar Dergisi, 2 (6), 207-223.

Erdağı Toksun, S. (2018). Okuma tür, yöntem ve teknikleri. Semra Alyılmaz, Berna Ürün-Karahan (Ed.), Okuma Eğitimi içinde (s. 75-105). Ankara: Anı Yayınları.

Erdem, C. (2012). Türk Dili ve Edebiyatı Öğretmen Adaylarının Okuma Stratejilerini Kullanma Düzeyleri. Uluslararası Türkçe Edebiyat Kültür Eğitim (TEKE) Dergisi, 1 (4), 162-186.

Fisher R. (1998). Thinking About Thinking: Developing Metacognition in Children. Early Child Development and Care, 141 (1), 1-15.

Gao, C., Terlizzese, T., Scullin, M. K. (2019). Short Sleep and Late Bedtimes are Detrimental to Educational Learning and Knowledge Transfer: An Investigation of Individual Differences in Susceptibility. The Journal of Biological and Medical Rhythm Research, 36, 307-318. https://doi.org/10.1080/07420528.2018.1539401

Göğüş, B. (1978). Orta Dereceli Okullarımızda Türkçe ve Yazın Eğitimi. Ankara : Kadıoğlu Matbaası.

Güneş, F. (2013). Türkçe Öğretimi Yaklaşımlar ve Modeller. Ankara: Pegem A.

Güngör, A., Ün Açıkgöz, K. (2006). İşbirlikli Öğrenme Yönteminin Okuduğunu Anlama Stratejilerinin Kullanımı ve Okumaya Yönelik Tutum Üzerindeki Etkileri. Kuram ve Uygulamada Eğitim Yönetimi, 48, 481-502.

Hourihan, K. L., Benjamin, A. S. (2013). State-based Metacognition: How Time of Day Affects The Accuracy of Metamemory. Memory, 22, 553-558. doi: 10.1080/09658211.2013.804091

Houtveen, A. A. M., van de Grift, W. J. C. M. (2007) Effects of Metacognitive Strategy Instruction and Instruction Time on Reading Comprehension. School Effectiveness and School Improvement, 18 (2), 173-190. doi: 10.1080/09243450601058717

iflazoğlu Saban, A., Saban A. (2008). Sınıf Öğretmenliği Öğrencilerinin Bilişsel Farkındalıkları ile Güdülerinin Bazı Sosyo-Demografik Değişkenlere Göre İncelenmesi. Ege Eğitim Dergisi, 9, 3558.

Jacobson, R. (1998). Teachers Improving Learning Using Metacognition With Self-Monitoring Learning Strategies. Education, 118 (4), 579-589.

Karadağ, R., Yurdakal, i. H. (2016). Okuma eğitimi. Fatma Susar Kırmızı (Ed.), ilk ve Ortaokullarda Türkçe Öğretimi içinde (s. 107-163). Ankara: Anı Yayınları.

Karatay, H. (2010). İlköğretim Öğrencilerinin Okuduğunu Kavrama ile ilgili Bilişsel Farkındalıkları. TÜBAR, 27, 457-475.

Karatay, H. (2014). Okuma eğitimi kuram ve uygulama. Ankara: Pegem A.

Kolić-Vehovec, S., Bajšanski, I. (2006). Metacognitive Strategies and Reading Comprehension in Elementary-School Students. European Journal of Psychology of Education, 21 (4), 439-451.

$\mathrm{Ku}, \mathrm{K} ., \mathrm{Ho}, \mathrm{I}$. (2010). Metacognitive Strategies That Enhance Critical Thinking. Metacognition Learning, 5, 251-267. doi: 10.1007/s11409-010-9060-6

Kuruyer, H. G., Özsoy, G. (2016). İyi ve Zayıf Okuyucuların Üstbilişsel Okuma Becerilerinin Incelenmesi: Bir Durum Çalışması. Kastamonu Üniversitesi Eğitim Fakültesi Dergisi, 24 (2), 771-788.

Mason, L., Santi, M. (1994). Argumentation Structure and Metacognition in Constructing Shared Knowledge at School. American Educational Research Association (AERA) Sempozyumu, New Orleans. https://files.eric.ed.gov/fulltext/ED371041.pdf

Mokhtari, K., Reichard, C. A. (2002). Assessing Students' Metacognitive Awareness of Rreading Strategies. Journal of Educational Psychology, 94, 249-259. 
Natale, V., Alzani, A., Cicogna, P. (2003). Cognitive Efficiency and Circadian Typologies: A Diurnal Study, Personality and Individual Differences. 35 (5), 1089-1105. https://doi.org/10.1016/S0191-8869(02)00320-3

O'Malley, J. M., Chamot, A. U. (1990). Learning Strategies in Second Language Acquisition. ABD: Cambridge Üniversitesi.

Ormrod, J. E. (2012). Human learning (Sixth Edition). New Jersey: Pearson.

Oxford, R. (1990). Language Learning Strategies: What Every Teacher Should Know. New York: Newbury House/ Harper \& Row.

Önder, I.., Beşoluk, Ş., Horzum, M. B. (2013). Psychometric Properties of the Turkish Version of the Composite Scale of Morningness. Spanish Journal of Psychology, 16, 1-10. doi: $10.1017 /$ sjp.2013.76

Önder, i., Horzum, M. B. \& Beşoluk, ş. (2012). Chronotype, Learning Approach, Type/Time of Instruction and Academic Achievement of The University Students. Luka Golovkin, Alexei Maliszkewicz (Ed.), Circadian Rhythms Biology, Cognition and Disorders içinde (s. 161-186). New York: Nova.

Özdemir, S. (2018). The Levels of Using Reading Strategies of the Prospective Teachers. Bartın Üniversitesi Eğitim Fakültesi Dergisi, 7 (1), 296-315.

Özsoy, G. (2008). Üstbiliş. Türk Eğitim Bilimleri, 6 (4), 713-740.

Özsoy, G., Günindi Y. (2011). Okulöncesi Öğretmen Adaylarının Üstbilişsel Farkındalık Düzeyleri. ilköğretim Online, 2, 430-440.

Özsoy, G., Çakıroğlu, A., Kuruyer, G. H. (2010). Sınıf Öğretmeni Adaylarının Üstbilişsel Farkındalık Düzeylerinin Bazı Değişkenler Bakımından Inncelenmesi. 9. Sınıf Öğretmenliği Eğitimi Sempozyumu, 20-22 Mayıs 2010, Elazı̆̆, 9.Ulusal Sınıf Öğretmenliği Eğitimi Sempozyumu Bildiri Kitabı İçinde (s. 489-492). Ankara: Tübitak.

Öztürk, E. (2012). Okuma Stratejileri Üstbilişsel Farkındalık Envanteri'nin Türkçe Formunun Geçerlik ve Güvenirlik Çalışması. Ilköğretim Online, 11 (2), 292- 305.

Padeliadu, S., Botsas G. \& Sideridis G. (2002). Metacognitive Awareness And Reading Strategies: Average and Readingdisabled Students, M. Makri-Tsilipakou (Ed.). 14th International Symposium selected papers on Theoretical and Applied Linguistics, 20-22 Nisan 2000, Yunanistan, Selected papers on theoretical and applied linguistics içinde (s. 307-318). Selanik: School of English-Aristotle University of Thessaloniki.

Palincsar, A., Brown, A. L. (1984). Reciprocal Teaching of Comprehension-Fostering and Comprehension-Monitoring Activities. Cognition and Instruction, 1 (2), 117-175.

Paris, S. G., Cross, D. R., Lipson, M. Y. (1984). Informed Strategies for Learning: A program to Improve Children's Reading Awareness and Comprehension. Journal of Educational Psychology, 76 (6), 1239-1252. http://dx.doi.org/10.1037/0022-0663.76.6.1239

Paris, S. C., Jacobs, J. E. (1984). The Benefits of Informed Instruction for Children's Reading Awareness and Comprehension Skills. Child Development, 55 (6), 2083-2093.

Pressley, M., Afflerbach, P. (1995). Verbal Protocols of Reading: The Nature of Constructively Responsive Reading. New York-Londra: Routledge .

Rothen, N., Meier, B. (2016). Time-of-day Affects Prospective Memory Differently in Younger and Older Adults. Aging, Neuropsychology, and Cognition, 24 (6), 600-612. doi: 10.1080/13825585.2016.1238444

Ruffing, S., Hahn, E., Spinath, F. M., Brünken, R., Karbach, J. (2015). Predicting Students' Learning Strategies: The Contribution of Chronotype Over Personality. Personality and Individual Differences, 85, 199-204. https://doi.org/10.1016/j.paid.2015.04.048

Schmitt, M. C., Hopkins, C. J. (1993). Metacognitive Theory Applied: Strategic Reading Instruction in the Current Generation of Basal Readers. Reading Research and Instruction, 32 (3), 13-24.

Sheorey, R., Mokhtari, K. (2001). Differences in the Metacognitive Awareness of Reading Strategies Among Native And Non-Native Readers. System, 29, 431-449. 
Smith, C. S., Reily, C., Midkiff, K. (1989). Evaluation of Three Circadian Rhythm Questionnaires with Suggestions For An Improved Measure Of Morningness. Journal of Applied Psychology, 74, 728-738.

Snow, C. E., Burns, S. M. \& Griffin, P. (1998). Preventing Reading Difficulties in Young Children. Washington: National Academy.

Şen, H. Ş. (2012). Ortaöğretim Öğrencilerinin Bilişüstü Yetileri Kullanma Durumlarının Bazı değişkenler Açısından Incelenmesi. Journal of Educational and Instructional Studies in the World, 2 (1), 2146-7463.

Temizkan, M. (2008). Bilişsel Okuma Stratejilerinin Türkçe Derslerinde Bilgiye Dayalı Metinleri Okuduğunu Anlama Üzerindeki Etkisi. Gazi Eğitim Fakültesi Dergisi, 28 (2), 129-148.

Topuzkanamış, E. (2009). Öğretmen Adaylarının Okuduğunu Anlama ve Okuma Stratejilerini Kullanma Düzeyleri. (Yayımlanmamış yüksek lisans tezi). Balıkesir Üniversitesi/Sosyal Bilimler Enstitüsü, Balıkesir.

Tüysüz, C., Karakuyu, Y., Bilgin, í. (2008). Öğretmen Adaylarının Üst Biliş Düzeylerinin Belirlenmesi. Abant Izzet Baysal Üniversitesi Sosyal Bilimler Enstitüsü Dergisi, 2 (17), 147-158.

Ülper, H. (2010). Okuma ve Anlamlandırma Becerilerinin Kazandırılması. Ankara: Nobel.

Yang, Y. F. (2002). Reassessing Readers' Comprehension Monitoring. Reading in a Foreign Language, $14(1), 18-42$.

Yavuz, D. (2009). Öğretmen Adaylarının Öz-Yeterlik Algıları ve Üstbilişsel Farkındalıklarının Çeşitli Değişkenler Açısından incelenmesi. (Yayımlanmamış yüksek lisans tezi), Zonguldak Karaelmas Üniversitesi/ Sosyal Bilimler Enstitüsü, Zonguldak.

Zhang, L. J., Wu, A. (2009). Chinese Senior High School EFL Students' Metacognitive Awareness and Reading Strategy Use. Reading in a Foreign Language, 21, 37-59.

\section{Introduction}

\section{Extended Abstract}

Cognitive strategies can be listed as note-taking, summarizing, elaboration of prior knowledge, inferencing, guessing, analyzing context clues; yet, metacognitive strategies are related to self-evaluation and thinking about reading as the learning process is based on regulation (Oxford, 1990; O'Malley and Chamot, 1990). Metacognition in reading involves self-monitoring and evaluation of one's own reading. The selection of appropriate strategies and skills for the text indicates the use of metacognitive skills in reading. Reading process begins with one's metacognitive skills and is completed with the use of reading strategies (Zhang and Wu 2009; Babbs and Moe, 1983).

One of the ways to enhance the effectiveness of reading process and to improve one's reading comprehension level is to ensure that the reader is capable of choosing appropriate strategies for the text and applying them. However, in applying these strategies, the ability of the reader to manage his/her own reading process and to find solutions for potential problems are related to the level of his/her metacognitive level. Analysis of the variables that affect the metacognitive awareness of reading strategies would enable individuals to improve their reading skills and also add to the relevant literature.

Analysis of the variables that affect the metacognitive awareness of reading strategies would enable individuals to improve their reading skills and also add to the relevant literature. For that reason, this study investigates the following research question: "Do the variables of gender, age and circadian rhythm characteristics significantly predict the university students' metacognitive awareness of reading strategies?".

\section{Method}

As the study looks into the relations between variables, it is a correlational study. The dependent variable of this study is participants' metacognitive awareness of reading strategies whilst the independent variables are the variables of gender, age and circadian rhythm characteristics, which are analyzed in relation to the dependent variable. 
A total of 818 students, who attended the initial teacher training in the Faculty of Education, Sakarya University, Turkey in the spring term of the 2015-2016 academic year, participated in the study. As the study seeks to reach all of the students who have received this training, it follows a maximum variation sampling method, which is one of purposive sampling methods to ensure the participation of students from different departments.

The data collection tools in the study are the metacognitive awareness of reading strategies inventory, the composite scale of morningness and personal information forms.

\section{Result and Discussion}

The variables of gender and age are in the first set of rows (block) in the hierarchical regression analysis. The results show that the variables of gender $(\beta=-, 18 ; p<, 01)$ and age $(\beta=, 10$; $p<, 01)$ significantly predict the metacognitive awareness of reading strategies. The variable of circadian rhythm is in the second row (block) in the analysis. When the variables of gender and age are controlled for, the variable of circadian rhythm significantly predicts the metacognitive awareness of reading strategies $(\beta=, 09 ; p<, 01)$.

The study concludes that the metacognitive awareness of female students towards reading strategies is higher. This difference in favor of female students may result from the characteristics of the selected sample group. It is notable that studies in the literature have not clearly identified the effect of the variable of gender on the skills related to metacognition. Therefore, further studies may examine the relation between gender and metacognitive skills with different sample groups.

The results of the study demonstrate that the older the individual is, the higher his/her metacognitive awareness towards reading strategies is. Remarkably, the effect of the variable of age on metacognitive awareness towards reading strategies has not been fully explored in the literature. Therefore, further studies may examine the relation between age and metacognitive skills with different sample groups.

In conclusion, the study shows that the preferences of students regarding circadian rhythm affect their metacognitive awareness towards reading strategies. The students who prefer a morningness circadian rhythm have higher metacognitive awareness towards reading strategies. Further studies should be done to address the preferences of individuals regarding circadian rhythm and their metacognitive skills and use of reading strategies. Therefore, further studies may examine circadian rhythm and different variables with different sample groups. 